\title{
CIDADE, MODOS DE USAR: UM ENSAIO SOBRE LEITURA
}

\author{
CITY, USER'S GUIDE - AN ESSAY ON URBAN LANDSCAPE
}

\section{Fábio Duarte}

Professor do mestrado em Gestão Urbana da PUC do Paraná, arquiteto e doutor em Comunicações pela USP e mestre em Multimeios (Unicamp). Foi pesquisador de doutorado em Desenvolvimento Regional (Université Laval, Canadá) e Geografia (Sorbonne, França).

e-mail: duarte.fabio@pucpr.br

\section{RESUMO}

Os conceitos de cidade e urbano são, muitas vezes, tomados como similares; mas é justamente em suas diferenças que estão as riquezas conceituais para análise das vivências urbanas. $A$ partir da análise de alguns autores (LYNCH) e críticos (SASAKI) das metodologias de leitura do espaço urbano, propomos a discussão das possibilidades de mapear a cidade não a partir de referências físicas, mas de suas vivências - nas quais os trabalhos de Georg Simmel, Lucrécia Ferrara e Armando Silva são discutidos. Nesse ponto, propomos os três conceitos operacionais: a cidade percebida, em que o foco é entender a cidade não pelo que ela se apresenta a nós, mas as representações que dela fazem seus habitantes; os rastros urbanos, os quais, por mínimos indícios, resgatamos as diversas vivências urbanas que se sobrepuseram e que ainda ecoam na cidade em que vivemos atualmente; e a cidade comunicada, na qual verificamos a interdependência existente na vivência urbana e suas representações do espaço urbano construído e o espaço simbólico inserido na cidade pelos meios de comunicação. Para ilustrar a intenção conceitual e metodológica deste ensaio, tomamos exemplos de trabalhos de leitura urbana realizados em Curitiba, Paraná.

Palavras-chave: Percepção ambiental, análise urbana, cidade comunicada, rastros urbanos, Curitiba.

\begin{abstract}
The terms urban and city are frequently taken as similar; but it is exactly in their differences that lay the conceptual strength for the analysis of urban experiences. From the main ideas of some authors (LYNCH) and critics (SASAKI) dedicated to the methodologies of urban reading, we discuss some possibilities of mapping the city not from physical references, but from people's experiences of the city - where the works by Georg Simmel, Lucrécia Ferrara and Armando Silva are discussed. At this point, we propose three operational concepts: perceived city, where the focus is on the understanding of the city from the representations that their inhabitants make of it; urban tracks, where through minimum indications we rescue the diversity of urban experiences that are overlapped and still echo in the city; and communicated city, where we verify the interdependence that has in the urban experience and its representations of the constructed urban space and the symbolic signs inserted in the city. To illustrate the conceptual and methodological intention of this essay, we take examples of our works of urban reading in Curitiba, Paraná.
\end{abstract}

Key words: Urban perception, urban analysis, communicated city, urban tracks, Curitiba. 


\section{O URBANO E SUAS CATEGORIAS ESPACIAIS}

Se nos propomos a analisar o meio urbano a partir da percepção das vivências de seus habitantes, buscando signos dos modos de usar a cidade e representações alternativas, devemos nos colocar uma pergunta essencial: qual a diferença entre cidade e urbano?

Muitas vezes tomados como termos similares, é justamente em suas diferenças conceituais que estão alguns dos pontos mais ricos (e complexos) a serem explorados. Leonardo Benevolo (1984, p. 15), ao iniciar sua reflexão sobre a cidade na história, busca-Ihe distinguir dois sentidos: "uma organização da sociedade concentrada e integrada, que começa há cinco mil anos no Próximo Oriente" ou "o cenário físico desta sociedade". Porém, mesmo essa distinção, sendo prática por permitir a compreensão de sociedades distantes, extintas ou anteriores à nossa pelos indícios físicos restantes de suas cidades, Benevolo logo argumenta que tal correspondência se perde na cidade moderna (a partir do final do século XIX) e a urbanização em escala mundial: "A cidade em que vivemos não é o reflexo fiel da sociedade no seu conjunto, mas um mecanismo mais rígido, que serve para retardar e para amortecer as transformações em todos os outros campos, para fazer durar mais tempo a hierarquia dos interesses consolidados." (BENEVOLO, 1984, p. 29)

A constatação de Benevolo de não haver uma correspondência direta entre a organização social urbana e sua materialização em uma cidade cujas formas a espelharia, ao menos a partir da modernidade, encontra discussão teórica aprofundada em Henri Lefèbvre. Para este, é possível identificar a principal característica da modernidade e contemporaneidade pela revolução urbana, que englobaria o "conjunto das transformações que a sociedade contemporânea atravessa para passar do período em que predominam as questões de crescimento e de industrialização (modelo, planificação, programação) ao período no qual a problemática urbana prevalecerá decisivamente, em que a busca das soluções e das modalidades próprias à sociedade urbana passará ao primeiro plano" (LEFÈBVRE, 1999, p. 19). Nesse sentido o autor define o fenômeno urbano (1999, p. 28), o qual sintetiza como o "urbano" e contrapõe ao termo "cidade" - esta como "um objeto definido e definitivo" - um campo de ações concretas, enquanto aquele como sendo, ao mesmo tempo, a síntese teórica das questões que marcam a sociedade contemporânea e uma "virtualidade iluminadora". Há, é claro, um diálogo de co-formação entre a sociedade urbana e cidade, mas não um espelhamento.

A compreensão, portanto, de o urbano abarcar conceitos, comportamentos, relações sociais, produtivas e tecnológicas, referenciais políticos e ideológicos que, ao mesmo tempo, moldam e refletem a sociedade contemporânea, e isso não se reflete diretamente na concretude da cidade, é suficiente para aceitarmos que a análise do meio urbano, pela leitura das formas da cidade, é um processo que reduz, de antemão, a complexidade e riqueza analítica. Para os profissionais que lidam com intervenções, planejamento e gestão urbanos, que têm como principal material de trabalho representações da cidade (mapas topográficos, cadastrais, de zoneamento, fotos, legislação, dados demográficos espacializados, plantas de infra-estrutura), é especialmente árduo entender que a dinâmica urbana, a qual percebem no contexto em foco de trabalho, não se manifesta diretamente nas formas legíveis da cidade e não é detectada pelas formas usuais de sua representação.

Isso sinaliza o desafio que temos, profissionais e pensadores envolvidos com as questões urbanas. Este trabalho pretende contribuir para essa discussão propondo conceitos operacionais para se ler o urbano na cidade.

\section{LER O URBANO NA CIDADE}

No final dos anos 50, Kevin Lynch (1999) fez uma das pesquisas pioneiras sobre a leitura do espaço urbano pelos cidadãos e sua sistematização conceitual e metodológica, chegando a um conjunto de elementos físicos preponderantes na criação de uma imagem da cidade. Tendo esse estudo por base, Ken-Ichi Sasaki (2000) discorda do privilégio atribuído à visualidade presente nos cinco elementos identificados por Lynch como estruturadores da cidade, 
principalmente quando são reforçados como receita para que uma cidade se torne de fácil apreensão e, assim, "bela". Na verdade, nesse estudo inaugural Lynch não preconiza esses elementos (vias, barreiras, regiões, cruzamentos e marcos referenciais) como partido de projeto; ele apenas detectou, a partir das entrevistas e desenhos de seus entrevistados, os elementos preponderantes e reincidentes que poderiam ser considerados como estruturais da imagem coletiva das cidades pesquisadas. $O$ que muito aconteceu foi o fato de, em novas pesquisas, desconsiderando as características específicas, tanto físicas quanto culturais das cidades, autores procurarem, a todo custo, identificar os cinco elementos de Lynch - e não perceberem que os elementos estruturais não são dados a priori, e sim resultantes da vivência urbana.

Nesse sentido, Sasaki propõe a idéia de tatilidade urbana, na qual a vivência corpórea traria o conhecimento mais profundo da cidade. Michel de Certeau (1996, p. 171) já havia debatido que no "corpo a corpo" dos pedestres com a cidade é que passamos a conhecêla, como se "uma espécie de cegueira caracterizasse as práticas organizadoras da cidade habitada". Nessa cegueira exploratória, portanto sem possibilidade de construção de uma visibilidade urbana, e convergente à apreensão tátil de Certeau (1996, p. 176), Sasaki coloca seu conceito de tatilidade urbana. Tendo a cidade de Tóquio e suas montanhas como exemplo, Sasaki afirma que o Monte Fuji, a quilômetros da cidade, é um ordenador determinante da paisagem urbana, e pode ser encarado como uma referência visual; porém, com mais força no cotidiano urbano estão as montanhas internas à cidade, sobre as quais ela se espalha, não se configurando, portanto, como referências visuais, mas sim - e isso é seu destaque - como referências táteis. Experiência semelhante de cidade montanhosa sem marcos visuais flagrantes, na qual a estrutura urbana geral para seus habitantes e o senso de localização ocorrem pela diferença de relevo, podemos encontrar em São Carlos, interior do estado de São Paulo, onde os bairros são identificados por serem altos ou baixos (estes junto de rios), e mesmo os poucos marcos referenciais na avenida principal estão bastante vinculados à sua distribuição no relevo.

Porém, Sasaki nos parece apresentar a mesma deficiência que ressalta, ao contrapor a tatilidade à "exclusiva" visibilidade observada nos estudos de Lynch: ele não apresenta alternativas metodológicas. Uma pergunta que sempre deveria ser posta a críticos - de preferência por eles mesmos, antes de publicarem suas idéias: se não isso, o que sugere?

O corpo, a tatilidade como forma de conhecimento urbano é uma idéia proveitosa, e com a relevância de outros elementos não-visualizáveis (como o imaginário) vêm sendo trabalhados como essenciais para se entender a percepção e o uso do espaço - incluindo, portanto, o espaço urbano. Porém, duas questões, interligadas, ficam em aberto: como representar a cidade tátil; e como tornar essa apreensão tátil em instrumental de análise, planejamento e gestão das cidades? Sem o enfrentamento dessas questões, a tatilidade urbana aparece como uma iluminação, mas ainda não uma idéia. Se não é possível generalizar um conhecimento e representá-lo de modo a outras pessoas terem acesso a ele por sua representação, de que vale apenas a argumentação, se há outro conhecimento possível? E se não se consegue sistematizar esse conhecimento e suas representações, de modo a torná-lo instrumental para análise e ação sobre tal objeto, há os riscos de:

a) Na análise, nunca haver um mínimo de fatores comuns que permitam comparar situações distintas;

b) na ação, asseverando haver um conhecimento ligado ao uso corpóreo da cidade, mas não o sistematizando, aceitar, tacitamente, nada se poder fazer; a vida urbana, seu planejamento e sua gestão são procedimentos vazios, os quais nunca conseguirão lidar com a multiplicidade das vivências urbanas.

Ora, claro que não pressupomos haver um planejamento centralizado a ditar como a cidade deva ser ou uma gestão que enquadre a vida urbana em estruturas definidas; mas não enfrentar o desafio conceitual e metodológico de criar instrumentos de análise e ação, a partir de uma idéia de a cidade ser os modos de vivenciá-la, é proteger-se em uma crítica arguta, mas que não avança. 


\section{CARTOGRAFANDO AS VIVÊNCIAS URBANAS}

Geógrafos, urbanistas, sociólogos e gestores urbanos têm, nos mapas, um instrumento fundamental de trabalho. Uma representação que, ante a impossibilidade de contato direto constante com a cidade, torna-se plano de reflexão e de ações urbanas. Há um distanciamento evidente entre o mapa da cidade e a cidade - e não há como ser diferente. Toda representação é algo que substitui um objeto a alguém, transmitindo algumas de suas características em sua ausência. Por meio de representação compreende-se um objeto sem ele estar presente. O caráter representacional é intrínseco a qualquer forma de reflexão, e portanto, instrumento de mediação também às ações sobre determinada realidade. Tendo isso claro, não há razão para se delongar em críticas condenatórias de os responsáveis pela ação, em um determinado ambiente, não terem contato com a realidade e tomarem suas decisões em gabinetes, enclausurados sobre representações frias do mundo real.

A reflexão e a ação sobre um meio, principalmente na escala urbana, sempre se farão mediadas por representações. Desse modo, a única questão realmente válida é: essas representações dão conta dos aspectos que se pretende trazer à reflexão e subsidiam ações de intervenção e gestão urbanas? Se não, por que não? E como contribuir?

Michel de Certeau (1996, p. 205) lembra que a forma representacional dos mapas atuais (com seus códigos, elementos aceitos, etc.) está diretamente ligada ao nascimento do discurso científico nos séculos XV ao XVII, e, aos poucos, deixou de estar ligada à marcação dos percursos que definiam um território, as etapas a cumprir e as distâncias medidas por dias de marcha. Tal codificação científica dos mapas fez com que essas representações tivessem vínculos cada vez mais estreitos e interdependentes entre si (os novos mapas atualizam os anteriores, os agrupamentos populacionais devem ser encaixados em regiões precisamente delimitadas, em mapas os quais, por sua vez, devem "casar" com a carta hidrográfica que será cortada no fim da área mapeável, independente das nascentes ou foz), nem sempre acompanhando as dinâmicas socioeconômicas, tecnológicas e culturais que reconstroem o espaço habitado.

O resgate de representar-se a complexidade e as singularidades das vivências urbanas é um tema constante não só das disciplinas que lidam diretamente com a cidade, mas também da filosofia. Heinz Paetzold (2000), ligando as metáforas filosóficas às cidades, argumenta que, enquanto René Descartes (no século XVII) defendia que a ciência seria mais coerente se pautada por um sistema lógico homogêneo de parâmetros, assim como as cidades barrocas e renascentistas, edificadas sob as ordens de único arquiteto inspirado por um único regente, Ludwig Wittgenstein (no século XX) discutia que a linguagem não se baseava em elementos semânticos básicos e originários, mas em jogos de linguagem provenientes de seu uso, os quais criariam possibilidades de linguagem, como subúrbios ou a formação espontânea das cidades antigas. Nessa mesma época, continua Paetzold, Ernst Cassirer e Georg Simmel defendem: nem a lógica científica ligada à física e à matemática nem os insumos da lingüística seriam suficientes para se tornarem modelos da filosofia contemporânea, mas tão somente quando essa filosofia tomar como instrumental as formas simbólicas e tornar-se uma filosofia da cultura.

A multiplicidade de singularidades mutáveis e interdependentes é que forma uma cultura, e, na cidade, essa é uma definição sucinta das vivências urbanas. Representar tais singularidades é um primeiro passo que já vem sendo dado por diversos pesquisadores a debruçarem-se sobre a percepção e leitura urbana; o desafio que se coloca cada vez mais é representar sistematicamente essa multiplicidade, esse coletivo de singularidades interdependentes, pois só com a sistematização de representações de coletivos estaremos aptos a fornecer insumos àqueles envolvidos em intervenção e gestão urbanas.

\section{CROQUIS URBANOS}

Colocarmo-nos como observadores do modo como as pessoas vivenciam essa região seria como se ocupássemos uma posição fora desse cotidiano, apenas descrevendo e analisando 
as maneiras como as pessoas usam a cidade, pareceria um distanciamento crítico que, na verdade, ocultaria a inevitável cultura do observador impregnando a observação e a análise. Nesse sentido, colher diretamente daqueles que vivem a cidade (moradores, trabalhadores, usuários esporádicos, passantes), suas próprias percepções e representações da vivência urbana, é fundamental.

Armando Silva (2003, p. 24) comenta que a riqueza dos croquis está em guardarem "os limites evocativos e metafóricos, aqueles de um território que não admite pontos precisos de corte, por sua expressão de sentimentos coletivos ou de profunda subjetividade social ". A passagem dos croquis aos mapas é um dos desafios para se instrumentar os processos de intervenção e gestão urbanas; porém, além de transportar às cartas urbanas o que foi desenhado nos croquis por aqueles que vivenciam uma região, é importante analisar os aspectos qualitativos desses croquis, desprendendo-se das escalas e eqüidistâncias geográficas para explorar indícios de vivências urbanas as quais se colocam no papel por escalas subjetivas, por proximidades afetivas.

Claro que, em um primeiro momento, corre-se o risco de buscar, nesses croquis, os elementos estruturais da leitura urbana propostos por Kevin Lynch (vias, barreiras, regiões, cruzamentos e marcos referenciais) - mas isso ofuscaria ao mesmo tempo a riqueza conceitual e metodológica de Lynch e a multiplicidade possível de abordagens provenientes dos habitantes, potencialmente variáveis de acordo com o contexto urbano, a cultura perceptiva da população e a relação entre essa cultura e o contexto.

A idéia, portanto, é, justamente, partir dos croquis e, sem quaisquer pressupostos classificatórios, estar atento às similaridades de leitura urbana que esses croquis possam apresentar - lembrando ser possível que, ao longo de diversas análises, encontremos categorias reincidentes, mas também, em diferentes contextos aos quais a pesquisa for aplicada, outras categorias de percepção podem surgir, seja pela cultura da população entrevistada, seja pelas variantes no contexto urbano.

Para fazer da análise dos desenhos instrumento de sistematização de leitura urbana, a ser incorporado em projetos de intervenção e processos de gestão urbanos, propomos três caminhos:

1 - Ao possuir um conjunto significativo de desenhos e conseguir agrupá-los em categorias definidas a partir de suas características gráficas, podemos ter idéia de como as pessoas apreendem determinada região - privilegiando seus trajetos cotidianos, por exemplo. Tal característica pode servir de guia para orientar intervenções urbanas, tanto as que interferem diretamente no sistema viário quanto aquelas que podem se apropriar dessa apreensão preponderante para se estabelecerem;

2 - ao deixar que os habitantes representem livremente o bairro, sem a restrição do código da palavra em entrevistas e a relação indissociável com o referente na fotografia, temos, no desenho, a possibilidade de vislumbrar relações subjetivas entre elementos físicos (vias, edifícios), comportamentais (trânsito) e imaginários (bairro arborizado, boemia). Como insumo a intervenções e gestão urbana de determinadas áreas, é possível destacar algumas dessas características que, se não são quantificáveis, guardam fagulhas da vivacidade da vivência urbana;

3 - ao analisar os desenhos, identificar todos os elementos representados que possam ser mapeados. Essa transposição do croqui, com forte carga subjetiva, para a exatidão da carta urbana, é o desafio e intuito principal deste estudo, buscando produzir mapas das vivências urbanas, os quais se tornem instrumentais para urbanistas, arquitetos e gestores urbanos.

\section{CONCEITOS OPERACIONAIS}

Importantes análises da paisagem urbana vêm sendo feitas no Brasil a partir das representações que os usuários de uma região fazem da cidade, usando diferentes metodologias fundamentadas nos trabalhos de Kevin Lynch (FERRARA, 1993; SANTOS, 1988). Mas essa pers- 
pectiva metodológica, a qual chamamos cidade percebida, traz-nos o seguinte questionamento: ela privilegia o presente, o modo como, hoje, as pessoas percebem um ambiente urbano.

Para ampliar a leitura da cidade, buscando nela traços do fenômeno urbano que a constitui, procuramos dois caminhos complementares: um que resgatasse indícios de uma cidade não mais existente em sua inteireza, mas ainda a determinar padrões urbanos e vivências atuais; e outro que identificasse, na cidade, atual projeções de como se pretende que ela seja e já estejam sendo aplicadas sobre a cidade atual, constituindo um imaginário urbano.

Assim, por um lado consideramos importante dar voz às pedras, buscar indícios na concretude da cidade que nos indicasse usos e vivências anteriores de uma região e que, ainda hoje, alimentam a vivência, percepção e representação da cidade. A esse encaminhamento metodológico chamamos rastros urbanos. Por outro lado, enfatizando que a percepção e representação da cidade estão diretamente ligadas a um imaginário urbano, e este ser formado por objetos e ações as quais não se inscrevem tradicionalmente no campo do urbanismo, mas operam pela projeção de signos de uma cidade desejada na cidade atual, buscamos identificá-los nos meios de comunicação - estratégia de pesquisa a que chamamos cidade comunicada. A seguir, desenvolvemos os três conceitos (cidade percebida, rastros urbanos e cidade comunicada), buscando ilustrá-los com alguns exemplos.

\section{Cidade percebida}

Da compreensão de como diferenças sociais, etárias e culturais daqueles que vivenciam uma região percebem, apreendem e incorporam em seu imaginário depende, em boa medida, o sucesso da implantação e gestão de projeto urbano.

A intenção de abrirmo-nos à compreensão da cidade pelas representações das pessoas as quais nela vivem, necessariamente deve assumir que a cidade concreta não é o único referencial. Isso pode parecer contraditório: afinal, a intenção não é analisar como as pessoas representam a cidade, e sim como percebem e representam essa percepção.

No primeiro caso, na análise da representação da cidade, teríamos, de um lado, uma cidade que está lá, a qual se conhece de antemão, e, de outro lado, representações as quais as pessoas fazem dessa cidade. A análise só permitiria relacionar representações múltiplas a uma cidade única, variadas a uma cidade definitiva, ou seja, o objeto cidade estaria fundamentalmente definido e dele pode-se representar o que se quiser, mas sempre será o que é: um parâmetro imóvel de análise.

Por isso é importante ressaltar que se trata, aqui, do segundo caso, da análise da percepção da cidade por aqueles que a vivenciam. Isso significa que consideramos ser a cidade tanto a sobreposição irregular das cidades anteriores a ela, nela, que foram o antes dela, como também a justaposição das vivências urbanas de seus habitantes e seus usuários. Estes, por sua vez, percebem a cidade por estímulos de elementos urbanos que dela "provêm", mas também a percebem por estímulos (imagens, desejos) os quais projetam sobre a cidade. A cidade se torna, assim, também, um caleidoscópio projetivo de várias e variadas percepções que a imantam, induzindo outras percepções e tornando-se cidade.

Vejamos, por exemplo, um bairro considerado violento, mesmo nele não ocorrendo mais crimes ou assaltos do que em outros. Mas as ruas são escuras e há uma favela. $\bigcirc$ primeiro sintoma indica apenas um problema de iluminação pública, que pode ser questão de número de luminárias, potência das luzes, ou arborização frondosa; o segundo sintoma, a favela, é uma formação territorial que indica problemas socioeconômicos e fundiários na cidade. No entanto, esses dois fatores podem dar a sensação de insegurança para quem vivencia esse bairro, e tais impressões são passadas de um para outro - e se, efetivamente, ocorre algum problema de violência, ele se impregna desses elementos relacionados, no imaginário urbano, à falta de segurança: cria-se, assim, a impressão de um bairro inseguro, oriunda da percepção dos moradores.

Assim, essas percepções urbanas são tanto apreensões de elementos concretos da cidade como projeções feitas sobre ela - e é na relação de reflexão e projeção de estímulos que se dá 
a percepção urbana, a qual direciona, por sua vez, as vivências urbanas e a idéia concebida de uma região.

A metodologia usada na cidade percebida, então, procura reter, daqueles que vivem uma região, alguns indícios do que absorvem e projetam sobre a cidade e formam sua percepção. Para a intervenção ou gestão urbana a cidade percebida nos parece fundamental, pois é nesse âmbito que uma atuação desatenta ou desastrada leva ao risco de frustrar um projeto o qual, no gabinete, demonstra sucesso.

Quando, aos moradores da região junto do rio Belém, o único inteiramente dentro do município de Curitiba e altamente poluído, foi pedido que desenhassem o rio na cidade, os resultados mostram a diversidade da percepção de um mesmo elemento urbano, como vemos nos desenhos abaixo.



Figura 1: Desenho de percepção - dentro do rio

Crédito: Autor e entrevistado anônimo

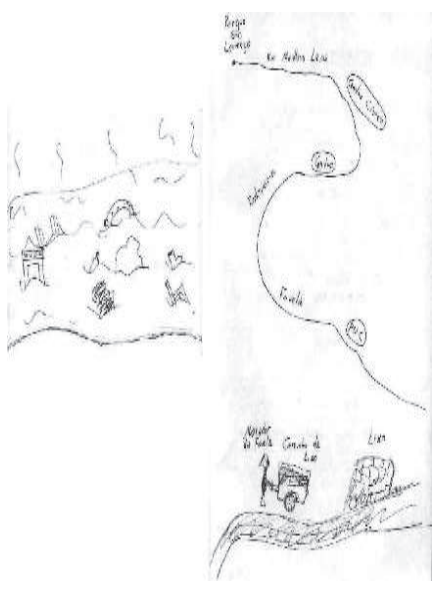

Figura 2: Desenho de percepção - o rio na cidade

Crédito: Autor e entrevistado anônimo

O desenho da Figura 1 é representante de um conjunto de desenhos de pessoas que enxergam o rio pontualmente e ligam-no exclusivamente à poluição. Não importa por onde ele passa (lembrando que a proposta era: "Desenhe o rio Belém na cidade de Curitiba"); a atenção exclusiva é que ele está visivelmente poluído, como mostram os elementos boiando.

Já o desenho da Figura 2 coloca o rio na cidade, ao sinalizar alguns pontos de passagem (Parque São Lourenço, Centro Cívico, PUC). Mas na parte inferior também há referência à polvição do rio; e o desenho é ilustrativo de um conjunto que explicita a visão preconcebida de os moradores da favela (Vila Torres) serem catadores de lixo (na verdade, há uma comunidade grande de catadores de papel), que causam, diretamente, a poluição do rio.

\section{Rastros urbanos}

"E percebemos que não somos mais do que os muitos que viveram nesses lugares."

Benedetta Tagliaube

A cidade é formada por uma sobreposição de camadas de outras cidades que existiram antes - ou melhor, a mesma cidade que se sobrepõe a si mesma, ao mesmo tempo reafirmando-se como única e distinguindo-se de si própria. A alma da cidade encontra-se na sobreposição de vivências urbanas que formam a cidade cotidianamente.

Parte dessas camadas é apagada pelas vivências que as sucedem; mas uma outra parte resta como seu testemunho. A busca de indícios dessas vivências tem menos a intenção de reconstituir o passado e entender mais como a cidade em que vivemos hoje é como é, em 
duas vertentes principais de análise: a) em qual medida e modo a cidade de ontem determina a cidade de hoje; e b) quais indícios da cidade de ontem podem direcionar ações sobre as vivências urbanas atuais.

Ambas as vertentes corroboram a necessária compreensão de, para se implementar alterações de usos, ser imprescindível entender que outros usos construíram a região tal como ela se encontra - talvez usos que não mais existam, mas deixaram rastros urbanos na região, rastros contidos na arquitetura de certas edificações, na implantação de outras (morfologia urbana), em remanescentes urbanos, no imaginário histórico impresso na cidade atual.

Vejamos alguns exemplos originários de pesquisas de leitura urbana desenvolvidas em Curitiba.

Nas duas imagens abaixo temos fragmentos de um uso urbano que já não mais existe, mas cujas marcas estão presentes na cidade. Na Figura 3, os trilhos de trem ainda marcam o pátio de manobra de uma concessionária de veículos; enquanto na Figura 4, em meio a um canteiro central, para cruzar um canal estreito e raso, uma robusta ponte de estrutura de ferro. Nenhum desses elementos tem qualquer função na cidade atual, mas indicam que, em algumas regiões, sua morfologia atual está calcada em usos os quais deixam seus rastros na cidade. Mesmo estando distantes mais de dois quilômetros, ambos os elementos são parte de uma região da cidade outrora marcada pela iniciante industrialização e pelo transporte férreo que trazia matéria-prima e levava produtos manufaturados.

A busca de rastros urbanos implica em vasculhar a cidade, procurando elementos que despertem dúvidas: $O$ que faz isto aqui? Por que esta rua tem esta forma? São tanto elementos concretos, a levarem-nos aos documentos históricos, quanto o caminho inverso, ao se analisar projetos ou planos antigos, que tinham um projeto urbano claro, e buscar, na cidade, seus indícios. Na Figura 5, desenho de Alfred Agache para Curitiba, de 1943, região do Centro Cívico - o qual já não mostra um rio que, hoje, surge canalizado e polvído e encontra razões históricas de planejamento para seu descaso urbano. As regiões do Rebouças e da bacia do rio Belém podem ser vistas na Figura 6.

\section{CIDADE COMUNICADA}

É ingenuidade imaginar que edifícios com destaque arquitetônico, alterações urbanísticas, mudanças na legislação e políticas socioeconômicas são auto-suficientes ou, mais ainda, são as únicas formas legítimas para promover mudanças e incrementos sociais, econômicos ou culturais, em detrimento da construção da imagem dessa região.

Há relações de interdependência entre o espaço urbano construído e o espaço simbólico. Mais ainda, poderíamos afirmar que a cidade "é o que é", tanto quanto dizem que ela é. Vimos

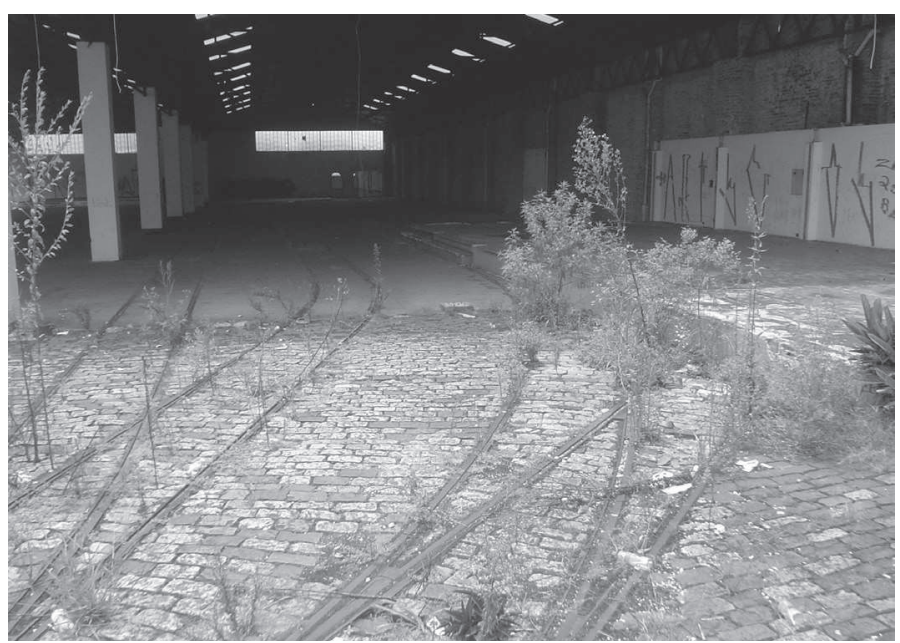

Figura 3:

Rastros dos trilhos

do bonde em

concessionária de

veículos, na praça

Eufrásio Corrêa, Centro

Crédito: Autor 


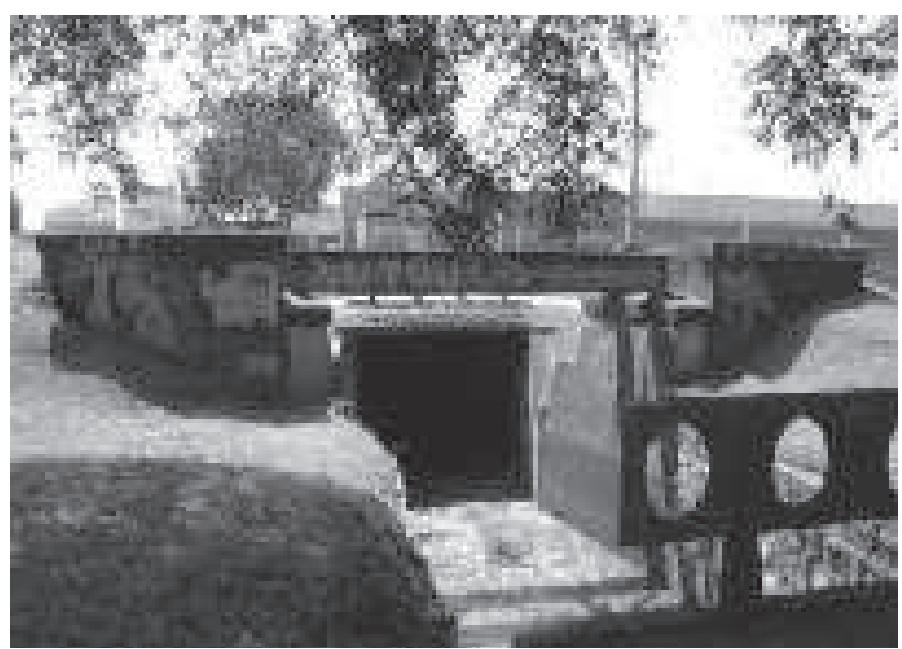

Figura 4:

Ponte férrea na rua João Negrão, Rebouças

Crédito: Autor

isso, em parte, na cidade percebida, formada pela apreensão de índices da cidade concreta, mas também de signos projetados sobre a cidade - que formam a cidade percebida, a cidade vivenciada. Se isso é verdadeiro para a cidade presente, aquela da vida cotidiana, quão forte não deverá ser a imagem de uma cidade desejada para ela se insirir na cidade mental, de modo a enxergar e viver a cidade que ainda não está lá. É o uso futuro da cidade que se busca inserir na cidade presente, para já formá-la no imaginário urbano.

A cidade comunicada se faz por reflexão ou projeção. Na primeira, busca-se verificar como uma determinada região aparece nos meios de comunicação, e, conseqüentemente, como ela é refletida de volta à cidade (pelos leitores ou telespectadores), influenciando o imaginário urbano de uma região. Na segunda se pode analisar, pelo material de marketing e divulgação, como projetos, em uma região urbana, são construídos e publicados para se inserir uma cidade desejada na cidade presente, de sorte que suas qualidades sejam incorporadas de antemão, mesmo imaginariamente.

A partir do ano 2000, a prefeitura de Curitiba lançou o Projeto Novo Rebouças, com a
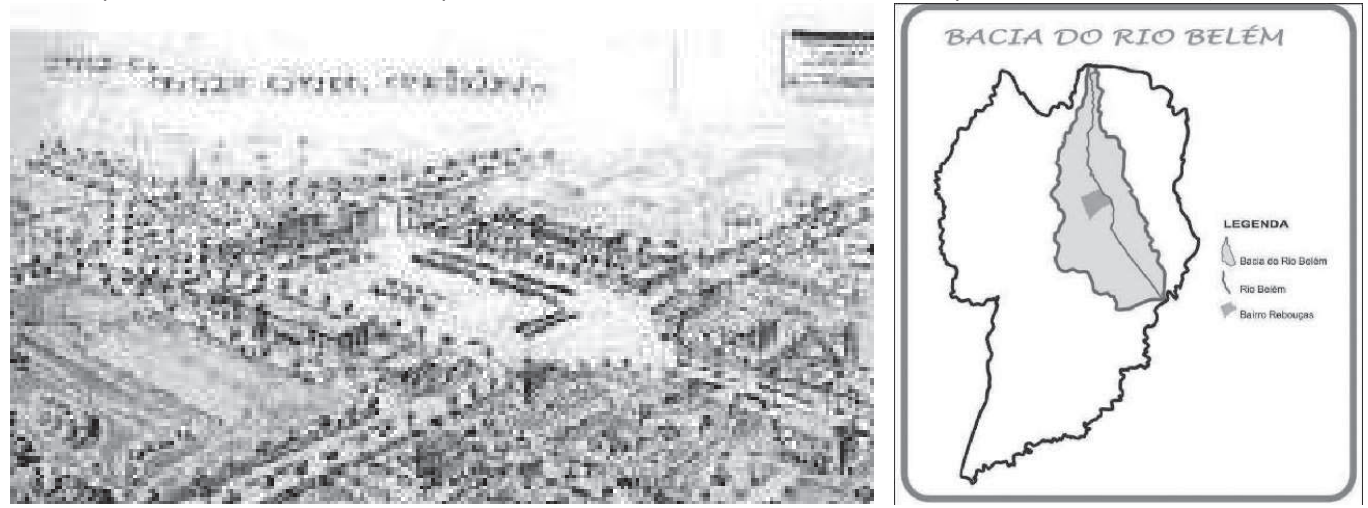

Figura 5: Alfred Agache. Desenho para o Centro Cívico de Curitiba, 1943

Figura 6: Localização das áreas de estudo - Bairro Rebouças e bacia do rio Belém

Fonte: Prefeitura de Curitiba

Crédito: Autor

intenção de revitalizar o antigo bairro industrial da cidade, onde há vários imóveis de grandes dimensões (antigas plantas fabris) desocupados, e torná-lo um pólo cultural. Para mostrar as intenções de grandiosidade do projeto, a prefeitura lançou um material de promoção e divulgação no início do projeto, no qual, antes de comentar-se qualquer coisa sobre o bairro, há uma linha do tempo em que aparecem alguns dos destaques urbanos pelos quais a cidade 
se tornou conhecida (como Ópera de Arame, Estações Tubo, Jardim Botânico, etc.), em uma intenção clara de atribuir a importância intencionada com o Projeto Novo Rebouças.

A iniciativa privada também se apropriou da força que vinha sendo dada pela prefeitura para a revitalização do Rebouças. O Shopping Estação, instalado em área junto da antiga estação ferroviária da cidade (incorporando-a ao projeto), quando da inauguração de seu centro de convenções, informava, no material de divulgação, que sua localização estava no Novo Rebouças (sic), o "SoHo de Curitiba", aludindo ao charme e prestígio da região novaiorquina que passou por um processo de renovação urbana nos anos 80 e 90 .

\section{CONCLUSÃO}

Como vimos defendendo neste estudo, é um desafio aos projetos de intervenção e gestão urbana analisar como as vivências urbanas estão impregnadas na cidade - tanto em sua concretude quanto nos modos de usá-las e no imaginário dos habitantes - de forma a integrar a leitura dessas vivências nos projetos de intervenção e processos de gestão desse ambiente urbano.

O espaço da cidade é formado por processos urbanos que tanto se sucedem na história quanto se inter-relacionam em uma mesma época e, com princípios diversos, forjam a cidade múltipla. A cidade é policrônica: seu tempo não é linear, muito menos causal, com o passado sendo condicionante absoluto do presente e tendo o futuro como conseqüência inevitável ou miragem distante.

A análise da cidade percebida, cidade comunicada e rastros urbanos procura mostrar as implicações de cada uma delas nas vivências urbanas, em como os habitantes usam, percebem e imaginam sua cidade. A história da cidade, nesse sentido, não é vista como o passado

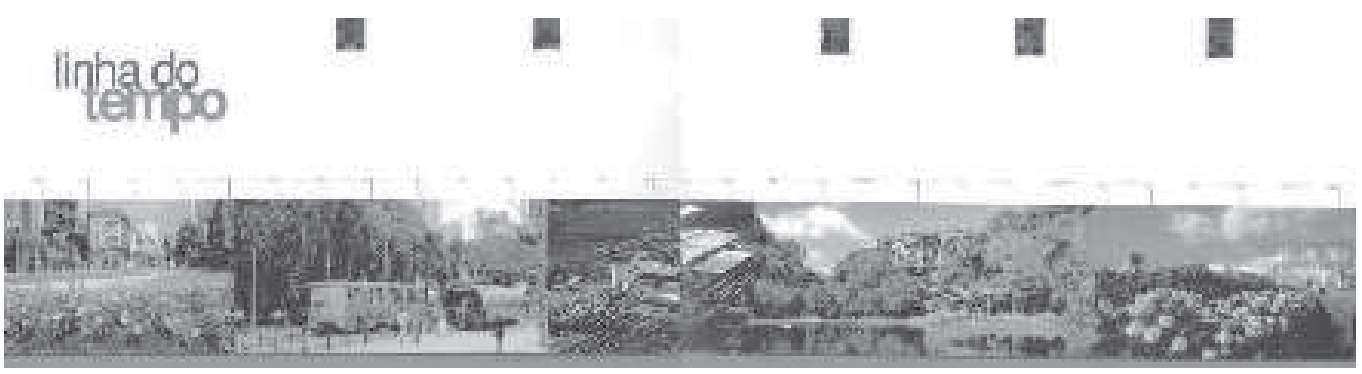

Figura 7: Projeto Novo Rebouças - Caderno de divulgação

Fonte: Prefeitura de Curitiba, 2000

urbano documentado. Seus elementos (físicos ou normativos) ainda presentes condicionam usos bloqueados pelo imaginário de um uso passado, o qual, mesmo que tenha perdido função, ainda é presente na percepção urbana, ou permanece ativo na cidade pela tradução de usos focada no presente. Nessa tradução de usos, muitas vezes, o que a impulsiona são as intenções de cidade, uma cidade futura projetada na atual, para que ela comece a materializar-se "antes" de ser construída. Assim, a cidade atual se constitui na imbricação de tempos urbanos distintos, ora articulando elementos a testemunharem o que ela foi, ora arremessando-se no sentido do que pretende ser.

Temos, então, que o espaço da cidade é constituído pelas relações entre objetos e ações as quais se apresentam, desde que passem por determinados filtros culturais. Propusemos o conceito de espaço (DUARTE, 2002) como matriz dos conceitos de território e lugar. Enquanto o primeiro (espaço) possibilitaria o contato sensorial e quase isento de significações com objetos e ações, e ao mesmo tempo se definiria por um alto grau de abstração conceitual, lugar e território seriam aproximações intencionais com esse espaço. Importantes pensadores 
que enfrentaram essa questão (FERRARA, 1986; SANTOS, 1997; CASEY, 1997) sempre admitiram que, no esforço analítico sobre o espaço (não importando a escala, seja a geopolítica internacional, seja o ambiente urbano), seu entendimento teria de passar por conceitos de aproximação, como território e/ou lugar.

Neste artigo sobre a leitura da cidade, partindo-se das vivências urbanas resgatando sua propriedade policrônica, o lugar é o instrumento conceitual que emerge. Os lugares da cidade são as porções do espaço apropriadas por pessoas ou grupos pela identificação afetiva ou cultural, não se restringindo às determinantes territoriais legais (dos bairros, por exemplo).

O desafio posto a partir do que trouxéssemos da cidade percebida, cidade comunicada e rastros urbanos, nos quais todos falavam de uma mesma e múltipla cidade, é: o sucesso de intervenções urbanas passa, necessariamente, pela constituição de lugares. E esta passa pela apropriação afetiva de uma porção do espaço, em que não importam as dimensões geográficas, e sim o conjunto de valores resgatados do passado naquela região ou desejados para que ela venha a ser, participando juntos, espacial e temporalmente, das vivências urbanas.

\section{Bibliografia}

BENEVOLO, Leonardo. A cidade e o arquiteto. São Paulo: Martins Fontes, 1984.

CASEY, Edward. The fate of place. Berkeley: University of California, 1997.

CERTEAU, Michel de. A invenção do cotidiano: Artes do fazer. Petrópolis: Vozes, 1996.

DUARTE, Fábio. Crise das matrizes espaciais. São Paulo: Perspectiva, 2002.

FERRARA, Lucrécia D’Aléssio. Estratégia dos signos. São Paulo: Perspectiva, 1986.

Olhar periférico. São Paulo: Edusp/Fapesp, 1993.

LEFÈBVRE, Henri. A revolução urbana. Belo Horizonte: Universidade Federal de Minas Gerais, 1999.

LYNCH, Kevin. Imagem da cidade. São Paulo: Edições 70, 1999.

PAETZOLD, Heinz. The philosophical notion of the city. In: MILES, Malcom; HALL, Tim; BORDEN, lain. The city cultures reader. Londres/Nova York: Routledge, 2000.

SANTOS, Carlos Nelson F. dos. A cidade como um jogo de cartas. São Paulo: Projeto, 1988.

SANTOS, Milton. A natureza do espaço. São Paulo: Hucitec, 1997.

SASAKI, Ken-Ichi. For whom is city design? Tactility vs visuality. In: MILES, Malcolm; HALL, Tim; BORDEN, lain (EE.). The city cultures reader. Nova York: Routledge, 2000.

SILVA, Armando. Imaginários urbanos. São Paulo: Perspectiva, 2003.

Obs.: $\bigcirc$ título deste artigo em inglês respeitou a versão inglesa para o título do livro de Georges Pérec: La vie, modes d'emploi. 